\title{
Primary sclerosing epithelioid fibrosarcoma of kidney with variant histomorphologic features: report of 2 cases and review of the literature
}

\author{
Dilek Ertoy Baydar ${ }^{* *}$, Kemal Kosemehmetoglu', Oguz Aydin², Julia A. Bridge³, Berrin Buyukeren ${ }^{1}$ \\ and Fazil Tuncay Aki ${ }^{4}$
}

\begin{abstract}
The authors present two cases of primary sclerosing epithelioid fibrosarcoma (SEF) of the kidney. Both patients had a mass in the upper part of the left kidney without any primary extrarenal neoplastic lesions. Grossly, the tumors were solid masses both measuring $7.5 \mathrm{~cm}$ in the greatest diameter. Histologically, one of the lesions exhibited a predominantly lobular growth of round or oval small uniform epithelioid cells in variable cellularity. Circular zones of crowded tumor cells alternating with hypocellular collagenous tissue in a concentric fashion around entrapped native renal tubules were distinctive. The second case was distinctive with significant cytological atypia in the neoplastic cells and prominent reactive proliferations in the trapped renal tubules. Immunohistochemically, vimentin, bcl-2 and MUC4 were diffusely positive in both. They were negative for S-100 protein, CD34, and desmin, whereas CD99 were positive in one lesion. Fluorescence in situ hybridization assay using dual staining probes detected EWSR1-CREB3L1 fusion in each lesion, which is characteristic molecular findings of SEF. One patient presented widespread distant metastases at the time of diagnosis. In the other, no tumor deposits were detected other than primary. Both patients have been alive with 30 and 10 month follow-ups, respectively. These tumors are 6th and 7th cases of primary renal SEF in the literature confirmed by FISH study, which exhibit unique and remarkable histomorphologic features.
\end{abstract}

Keywords: Sclerosing epithelioid fibrosarcoma, Kidney, EWSR1, CREB3L1, Translocation

\section{Background}

Sclerosing epithelioid fibrosarcoma (SEF) is a rare malignant mesenchymal tumor of soft tissues composed of cords, nests or sheets of relatively monotonous epithelioid cells within a collagenous background. It has recently been characterized by recurrent FUS-CREB3L1, FUS-CREB3L2 or EWS1-CREB3L1 translocations and immunohistochemical MUC4 expression [1-3]. The tumor occurs over a wide age spectrum at initial presentation without sex predilection. Most reported cases are in the soft tissue of extremities and limb girdles [4-7]. Primary SEF in visceral organs is exceedingly rare, with only a few cases reported.

Here, we present two cases of SEF with primary renal origin bearing a EWS1-CREB3L1 gene fusion, as

\footnotetext{
* Correspondence: dertoy@hacettepe.edu.tr

'Department of Pathology, Hacettepe University Hospital, Ankara, Turkey

Full list of author information is available at the end of the article
}

supported by MUC4 immunostaining and fluorescence in situ hybridization (FISH). To our knowledge, these are the sixth and seventh genetically confirmed cases of SEF reported in the kidney following very recently described primary renal SEF(s) by Arbajian et al., Argani et al. and Ohlmann, et al. $[1,8,9]$. Some of their morphologic features are unique and deserve to be noted for full characterization of this entity in a new environment.

\section{Case presentation}

Two cases of SEF that were found to harbor EWSR1CREB3L1 fusion were encountered in the diagnostic practice of the authors. The clinical records were retrieved for analysis, and all available pathologic materials were reviewed. 
Table 1 Features of the antibodies used for the immunohistochemical stains

\begin{tabular}{ll}
\hline Antigen & Clone, dilution, source \\
\hline Pan-Cytokeratin & AE1/AE3, 1:200, Leica, Newcastle/UK \\
Epithelial Membrane Antigen & E29, 1:300, Biocare, Concord/CA \\
PAX8 & PAX8, 1:100, Biocare, Concord/CA \\
WT1 & 6 F-H2, 1:40, DBS, Pleasenton/CA \\
ER & EP1, 1:100, Genemed, San Francisco/CA \\
PR & SP2, 1:1000, Thermo, Fremont/CA \\
CD34 & QBEND/10, 1:100, DBS, Pleasenton/CA \\
SMA & 1A4, 1:1000, NeoMarkers, Fremont/CA \\
Desmin & D33, 1:50, Biocare, Concord/CA \\
S100 protein & Z0311, 1:6000, DAKO, Glostrup/Denmark \\
GFAP & GA-5, 1:50, Thermo, Fremont/CA \\
BCI2 & BCl-2-100, 1:80, Invitrogen, Paisley/UK \\
CD99 & HO36-1.1, 1:100, Thermo, Fremont/CA \\
MUC4 & 1G8, 1:50, Invitrogen, Paisley/UK \\
HMB45 & HMB45, 1:25, DBS, Pleasenton/CA \\
Melan-A & A103, 1:100, Thermo, Fremont/CA \\
INI1 & 25, 1:50, Zeta, Arcadia/CA \\
\hline
\end{tabular}

\section{Immunohistochemistry}

For immunohistochemical labeling, a polymer detection system (Leica, DS9800) and the BOND-MAX automated immunostainer was used. The standard antibodies consumed, vendors, and dilutions were summarized in Table 1.

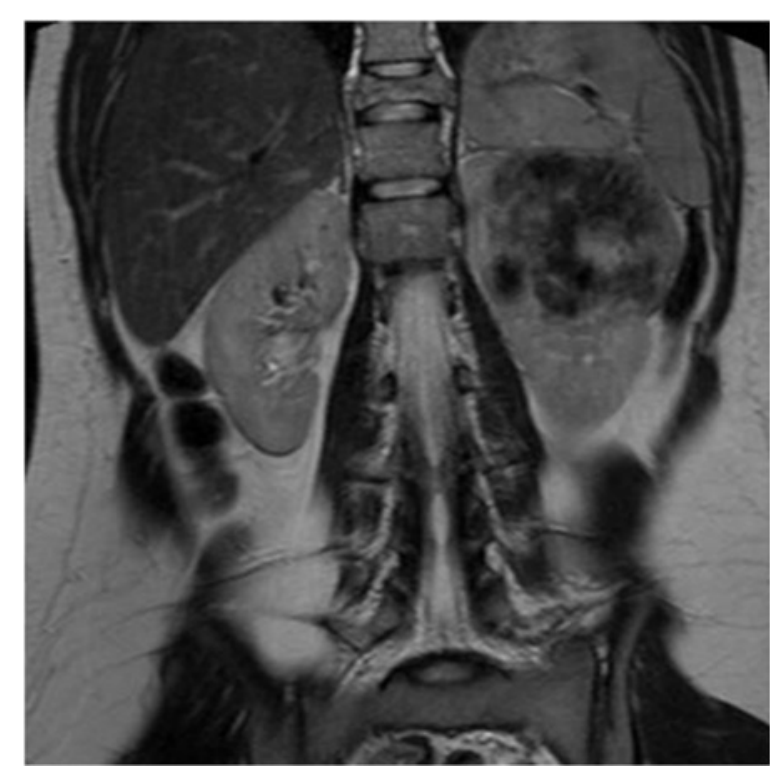

Fig. 1 Case \#1. Computerized tomography scan showing a large tumor in the left kidney

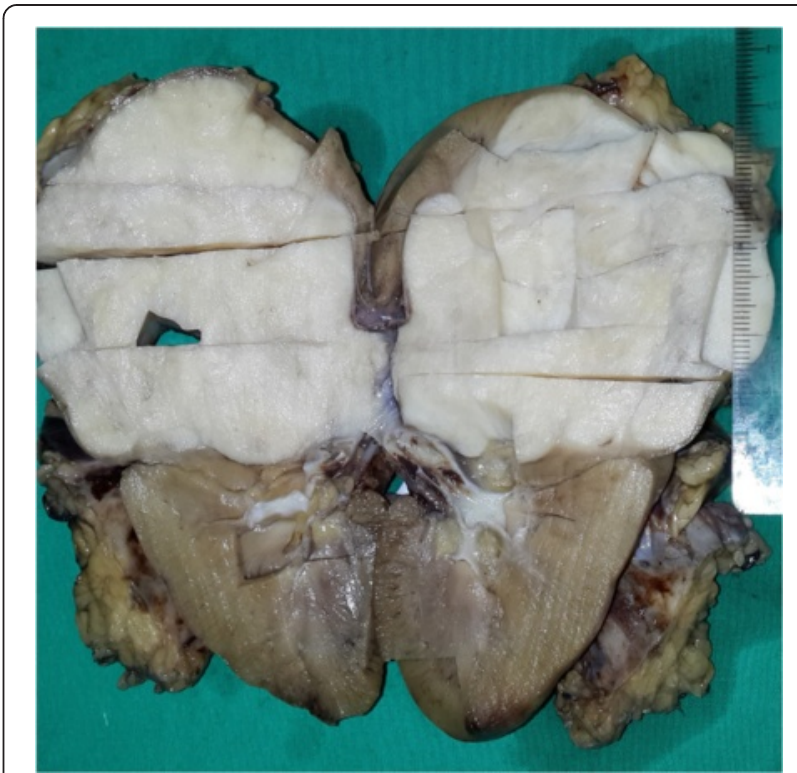

Fig. 2 Case \#1. Solid white tumor filling out the upper half of the kidney

\section{Fluorescence In Situ Hybridization (FISH)}

FISH analysis was performed on representative 4-5 $\mu \mathrm{m}$ thick unstained formalin-fixed, paraffin-embedded tissue sections of the tumor samples of each case. For characte rization of the possible underlying gene rearrangement or fusion gene events, the following FISH probe sets were utilized on both cases: Vysis LSI EWSR1 (22q12) and Vysis LSI FUS (16p11) Dual Color Break Apart Probes

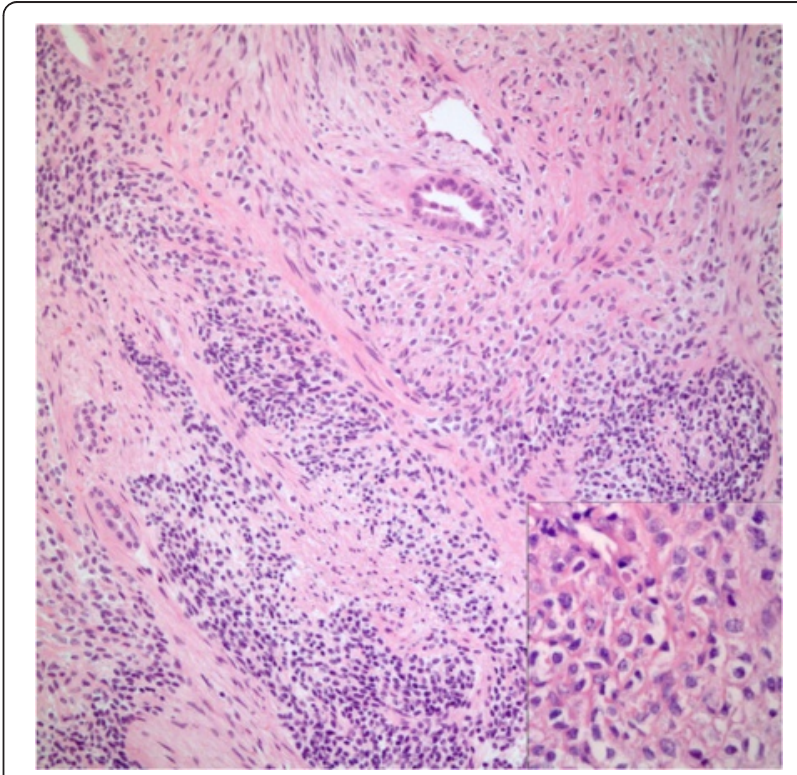

Fig. 3 Case \#1. Alternating hypercellular and a hypocellular areas of neoplastic cells with monomorphic ovoid nuclei and indistinct pale to clear cytoplasm (H\&E x 200; inset: H\&E x 400) 


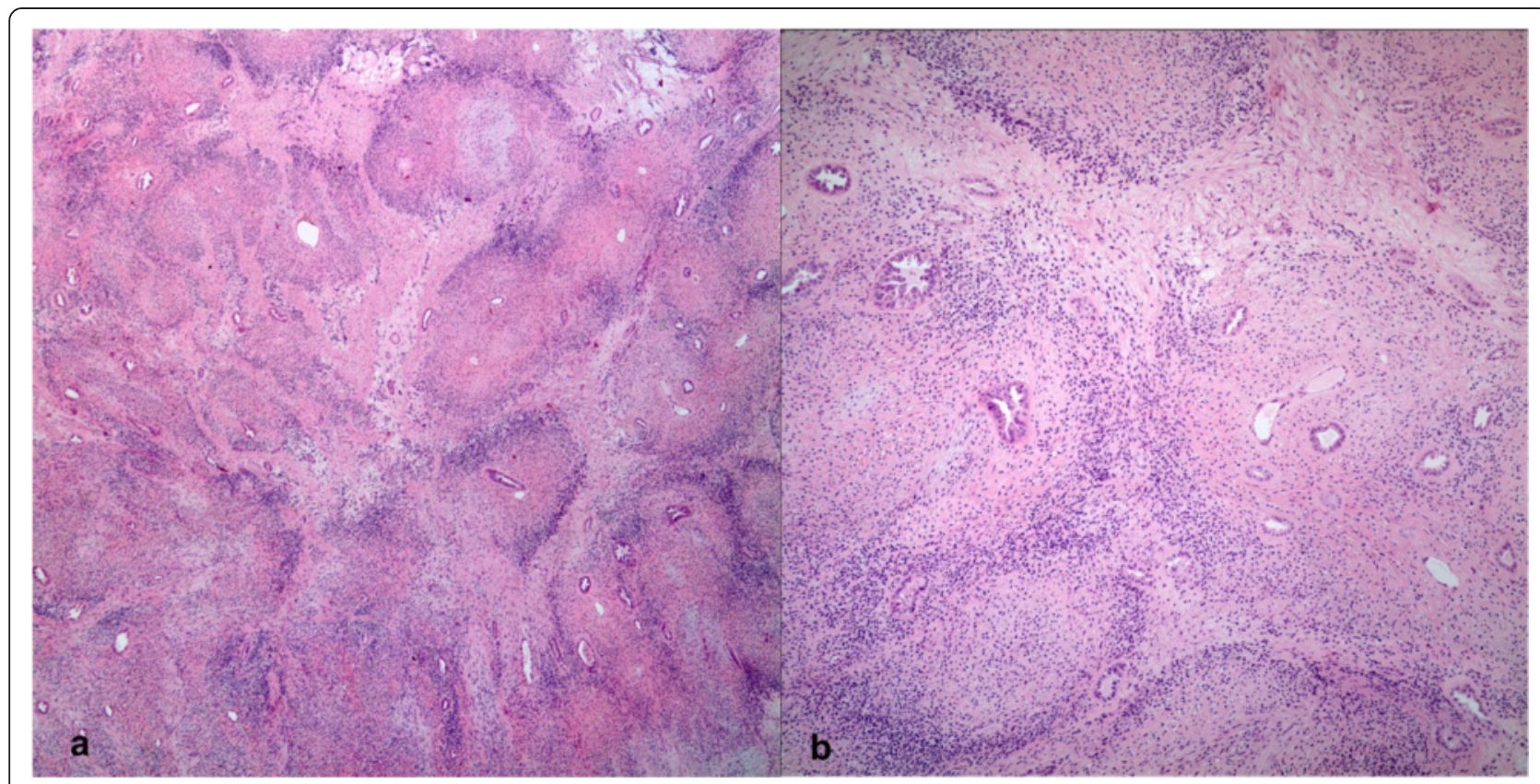

Fig. 4 Case \#1. a Lobular/micronodular pattern (H\&E x 40). b Concentric hypocellular inner, hypercellular outer zone around entrapped renal tubules (H\&E x 100)

(Abbott Molecular, Inc., Des Plaines, IL) and EWSR1 and CREB3L1 spanning probe sets using cocktails of BAC clones (RP11-945 M21 and RP11-1126O13, and RP111014A16, RP11-1106 J11 and RP11-481I24 respectively) selected on the basis of their location per the UCSC Human Genome Browser [http://genome.ucsc.edu/cgibin/hgGateway] and obtained from BAC/PAC Resources Center (Children's Hospital Oakland Research Institute, Oakland, CA, USA).

Hybridization studies using the Vysis LSI Dual Color Break Apart Probes for the assessment of rearrangement of the FUS and EWSR1 loci were performed following the manufacturer's instructions (Abbott Molecular, Inc., Des Plaines, IL). With respect to the custom spanning probes, each BAC clone was directly labeled by nick translation with either Spectrum Green- or Spectrum Orange-dUTP per the manufacturer's protocol (Abbott Molecular, Inc., Des Plaines, IL). An amount of 3 ug of DNA for each probe or $1.5 \mathrm{ug}$ for each of two probes were combined. All nick translation reagents were then multiplied by the total ug of DNA used in the cocktail. Amounts of $200 \mathrm{ng}$ of each probe were hybridized to the target DNA and blocked with approximately 15 fold excess of a combination of Human Cot-I DNA (Invitrogen, Carlsbad, CA) and human placental DNA.

Prior to hybridization, the slides were pretreated at room temperature in $0.2 \mathrm{~N} \mathrm{HCl}$ for $20 \mathrm{~min}$, washed in water for $3 \mathrm{~min}$, incubated at $80{ }^{\circ} \mathrm{C}$ for $25 \mathrm{~min}$ in VP 2000 Pretreatment Reagent (Abbott Molecular, Inc., Des Plaines, IL) and then washed again in water for $3 \mathrm{~min}$.
Subsequently, the slides were incubated for $15 \mathrm{~min}$ at $37^{\circ} \mathrm{C}$ in protease solution $[25 \mathrm{mg}$ of protease in $50 \mathrm{ml}$ of protease solution (Abbott Molecular, Inc., Des Plaines, IL), washed in $1 \times$ PBS at room temperature for $5 \mathrm{~min}$ and then dehydrated in gradient ethanol $(75,85$, and $100 \%)$ at room temperature for $1 \mathrm{~min}$ each and air-dried. After the cells and probes were co-denatured at $80{ }^{\circ} \mathrm{C}$ for $10 \mathrm{~min}$ and incubated overnight at $37^{\circ} \mathrm{C}$ using the HYBrite ${ }^{\mathrm{mm}}$ system (Abbott Molecular, Inc., Des Plaines, IL), post-hybridization washing was performed in $2 \times \mathrm{SSC} / 0.1 \% \mathrm{NP}-40$ at $72{ }^{\circ} \mathrm{C}$ for $2 \mathrm{~min}$, followed by $2 \times \mathrm{SSC} / 0.1 \% \mathrm{NP}-40$ at room temperature for $1 \mathrm{~min}$. The slides were then counterstained with DAPI II (Abbott Molecular, Inc., Des Plaines, IL). To confirm correct mapping, optimal signal strength, and lack of cross-hybridization, each probe set was also hybridized to metaphase cell preparations of karyotypically normal peripheral blood lymphocytes before proceeding with analysis of the patient samples.

The cutoff level for scoring a specimen as positive for a rearrangement of the FUS or EWSR1 locus or as positive for an EWSR1/CREB3L1 fusion was $>15 \%$ of the cells evaluated. Images were prepared using the Cytovision Image Analysis System (Applied Imaging, Santa Clara, CA). For each probe set, 100-200 interphase nuclei with strong and well-delineated signals were examined.

\section{Case 1}

The patient was a 16-year-old girl who presented at the urology clinics with pain on the left side of the abdomen radiating to the back. Her past medical history was 


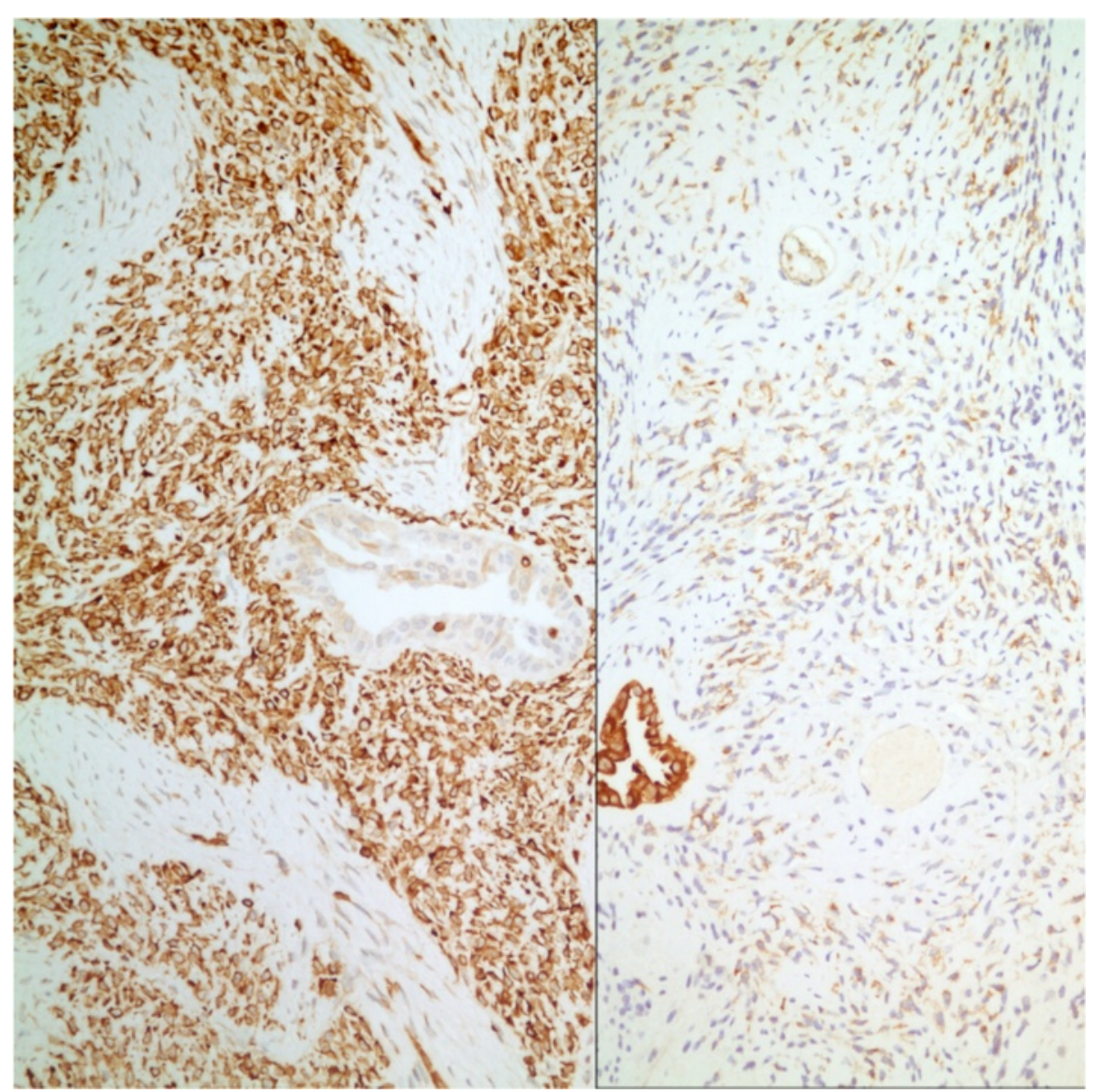

Fig. 5 Case \#1. Strong bcl-2 and weak EMA expression by neoplastic cells (Left: Immunohistochemistry, anti-bcl-2 Ab x 200; Right: Immunohistochemistry, anti-EMA Ab x 200)

insignificant. Computerized axial tomography scans of the chest, abdomen, and pelvis revealed a $70 \times 70 \times 60 \mathrm{~mm}$ left renal mass (Fig. 1), bilateral pulmonary nodules (the largest being $16 \mathrm{~mm}$ in diameter), and widespread bone metastases in vertebrae, sacrum and left femoral head. A biopsy from the tumor in the kidney through laparotomy was performed followed by left radical nephrectomy after the diagnosis of malignancy.

Tumor occupied the entire upper half of the kidney, extended into the renal sinus, was a solid white unencapsulated lesion with sharp borders, measuring $7.5 \times 7 \times 7 \mathrm{~cm}$ in size (Fig. 2). Microscopical sections showed diffuse infiltration of the neoplastic tissue in kidney parenchyma separating normal renal elements from each other. The neoplastic cells were small, monotonous and epithelioid with clear to pale eosinophilic cytoplasm, and were arranged in single files, cords, nests or irregular aggregates in collagenous matrix (Fig. 3). Nuclei were generally round to oval, with indistinct nucleoli. Hypercellular areas alternated randomly with hypocellular densely hyalinized or at times myxoid stroma. Additionally, a peculiar lobular organization was noted in many regions where a renal tubule in the center was surrounded by concentric inner hypo and outer hypercellular zones of neoplastic cells (Fig. 4a and b). These lobules were separated from each other by myofibroblasts. Tubules entrapped in the tumor were lined by single layered Pax- 8 positive cuboidal cells without atypia, some showed shallow papillary hyperplasia and rare mitosis. Mitotic rate was $1 / 10 \mathrm{hpf}$ in the neoplasm and there were occasional areas of necrosis in the tumor. Hypercellular areas occasionally contained vague nodules of collagen mimicking those seen in hyalinizing spindle cell tumor with giant rosettes (HSCTGR). The surrounding kidney showed no specific pathologic changes. By immunohistochemistry, neoplastic cells were immunoreactive diffusely and strongly for vimentin, bcl-2 and CD99; EMA labelled them in a weak and patchy fashion (Fig. 5). They were negative for pan-cytokeratin, Pax-8, WT-1, CD34, S-100, GFAP, Melan-A, HMB-45, desmin, and estrogen and progesterone receptors. Smooth muscle actin (SMA) stained myofibroblastic cells in-between the neoplastic lobules (Fig. 6). INI-1 was preserved. Then, an 


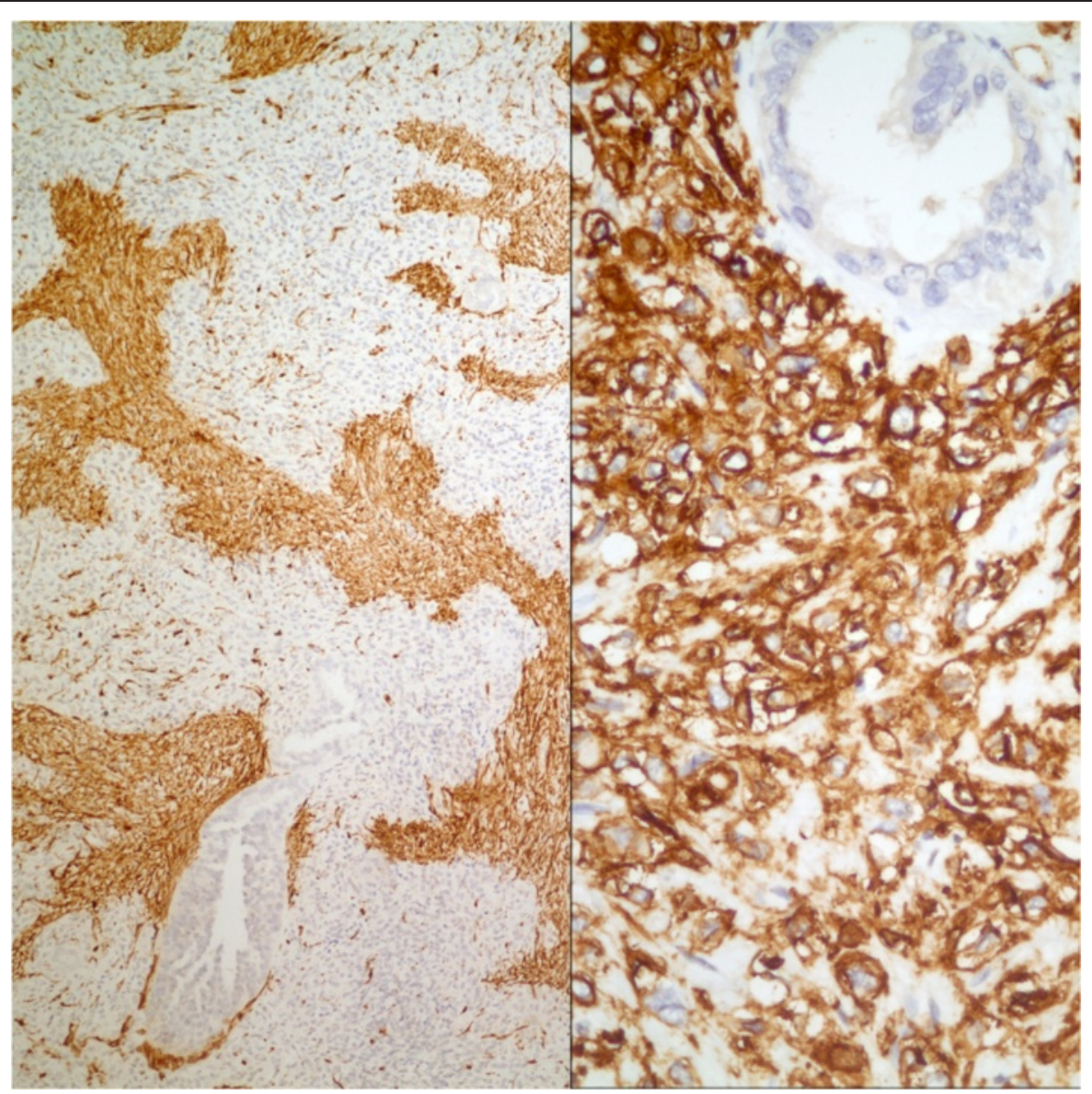

Fig. 6 Case \#1. SMA stains myofibroblasts between neoplastic lobules and MUC4 stains neoplastic cells (Left: Immunohistochemistry, anti-SMA Ab x 100; Right: Immunohistochemistry, anti-MUC4 Ab x 400)

immunohistochemical stain for MUC4 was performed which showed strong positivity throughout the tumor (Fig. 6). Finally, FISH analysis with the EWSR1 Break Apart probe revealed loss of one copy of the Spectrum Green labeled probe flanking the 3' (telomeric) side of the EWSR1 gene as well as the presence of a single fused EWSR1/CREB3L1 signal (represented by a juxtaposed orange signal and green signal) consistent with the presence of an unbalanced der(22)t(11;22)(p11;q12) (Fig. 7), confirming the diagnosis of sclerosing epithelioid fibrosarcoma. FISH study was negative for a rearrangement of the FUS gene locus.

Patient was given chemotherapy with multiple agents. She is alive with disease after 30 month follow-up.

\section{Case 2}

The patient was a 57-year-old woman who was investigated for cholelithiasis due to dyspeptic complaints. During abdominal ultrasonography, she was found to have a left renal mass incidentally. The CT scan showed that the tumor was located at the upper pole of the kidney and was measured
$6 \mathrm{~cm}$ in the largest diameter. Her past medical history was unremarkable except for hypertension, congestive heart failure and arrhythmia. Serum and urine tests were within the normal limits. The patient subsequently underwent open left partial nephrectomy.

On gross examination, the specimen had an unencapsulated, solid - white firm tumor with irregular borders, measuring $7.5 \times 5.5 \times 4 \mathrm{~cm}$ (Fig. 8). Histologic examination revealed that tumor contained abundant entrapped native renal tubules throughout as in the first case, mimicking a biphasic neoplasm (Fig. 9). These tubules were hyperplastic and proliferating, were of various size and shapes, some being cystic or leaf-like, and lined by single layered cuboidal or occasionally flattened cells, all expressing nuclear Pax-8. Intraluminal papillary projections were common, but without cytologic atypia. Neoplastic component had a variable cellularity (Fig. 10). Hypocellular regions contained abundant hyalinized collagen and some showed myxoid change. Hypercellular areas were divided into anastomosing compartments by sclerotic collagen bands. Neoplastic cells were polygonal epithelioid or plump 


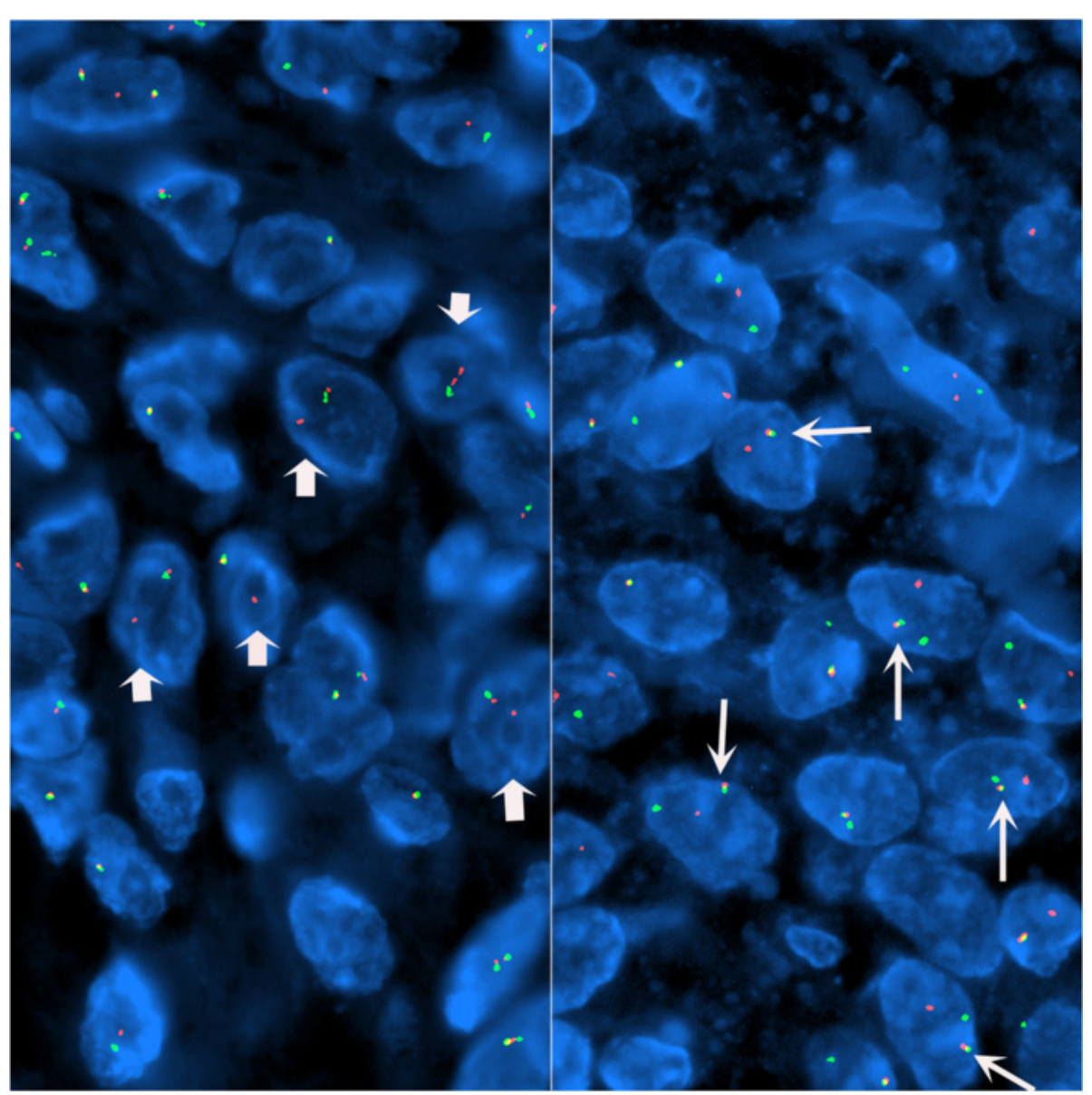

Fig. 7 Case \#1. An EWSR1 Break Apart probe set and a custom probe set spanning the EWSR1 (Spectrum Orange) and the CREB3L1 (Spectrum Green) loci demonstrating loss of the Spectrum Green labeled probe signal that flanks the 3' (telomeric) side of the EWSR1 locus (short arrows, left panel) and a single fusion signal (long arrows, right panel)

spindle type forming short fascicles (Fig. 11). Cytoplasm was clear or eosinophilic. Cellular pleomorphism was prominent with scattered bizarre and hyperchromatic nuclei, intranuclear inclusions were evident in some. Tumor abutted lining urothelium of renal pelvis without ulceration and formed large hypocellular sheets of short spindle cells in myxoid matrix encircling pelvic wall. There were rare foci of necrosis. Mitotic rate ranged 5-10/ $10 \mathrm{hpf}$. Immunohistochemical profile of tumor was similar to the first case including strong and diffuse MUC4, vimentin and bcl-2, weak EMA expression (Fig. 12) except negative immunoreactivity for CD99. SMA showed frequently scattered myofibroblasts between the tumor cells. FISH demonstrated an unbalanced $\operatorname{der}(22) \mathrm{t}(11 ; 22)(\mathrm{p} 11 ; \mathrm{q} 12)$, as in the case \#1 (Fig. 13). A FUS gene rearrangement was not identified.

The lesion occupied both renal cortex and medulla, and invaded into peripelvic and perirenal fat tissue. As one of the surgical margins was in continuation with the tumor, the patient underwent left radical nephrectomy which showed $1 \mathrm{~cm}$ residual mass. No adjuvant treatment was given. Patient is alive without local or distant recurrence 10 months after surgery.

\section{Discussion}

Sclerosing epithelioid fibrosarcoma (SEF) was first described by Meis-Kindblom et al. in 1995 [6]. The most SEFs are deep seated lesions with a wide age range, but typically occurring in middle aged adults $[4,6]$. The most frequent sites of involvement are deep soft tissues of lower extremities or limb girdle followed by trunk, upper extremities, and head and neck region, although primary SEF of unexpected locations such as bone, retroperitoneum, and pelvis were also described as case reports or small series [10-13]. Primary SEF in visceral organs is exceedingly rare, with only a single case reports in the liver [12], the lower gastrointestinal tract [11], the ovary [14], and the pancreas [10]. Occurrence of primary renal SEF was proven by Argani et al. who have recently reported 2 well-documented cases with rearrangement involving 


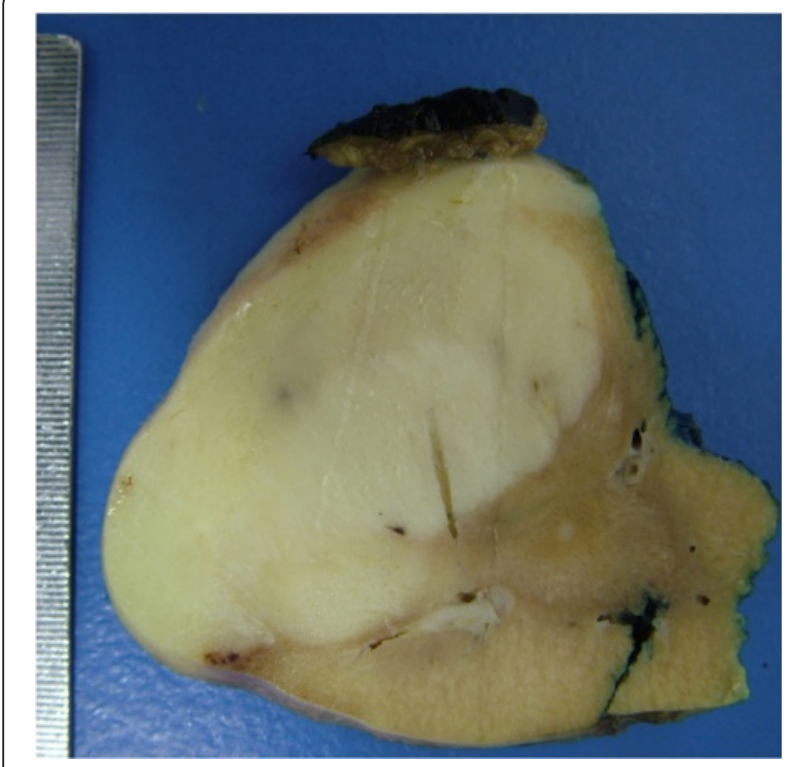

Fig. 8 Case \#2. Gross photograph of the kidney in patient no. 2 shows a well-defined solid mass that extends to surgical margin of the partial nephrectomy specimen
EWSR1 and CREB3L1 genes [8] (Table 2). There are also 3 additional cases in the literature described as primary renal SEFs which were shown to express MUC4 [1,9]. Two of these had rearranged EWSR1 with undocumented fusion gene partner.

SEF is a difficult diagnosis in visceral organs because of its rarity and its epithelioid appearance, closely mimicking carcinomas. It is characterized by a proliferation of epithelioid cells arranged in nests and cords in a densely hyalinized stroma (Table 3). Neoplastic cells are positive for vimentin, bcl-2, MUC4, weakly and focally for epithelial membrane antigen (EMA), and are negative for broad spectrum cytokeratins, smooth muscle actin, desmin, CD34, S-100 protein, HMB45 and melan-A [2, 4, 15]. MUC4 itself has been recently reported as highly specific for the diagnosis of SEF [2]. Strong CD99 expression is seen in some cases. Most common genetic alteration described in pure SEFs is EWSR1-CREB3L1 fusion [1]. Basic histomorphological differentials of SEF will be a variety of tumors with epithelioid and sclerotic features, mainly primary or metastatic carcinoma. Epithelioid angiomyolipoma, metanephric stromal tumor and synovial sarcoma are the other considerations in the differential diagnosis, as well as sclerosing clear cell sarcoma of the kidney (CCSK) being the most challenging. A battery of immunohistochemical stains will help for further characterization in most circumstances,

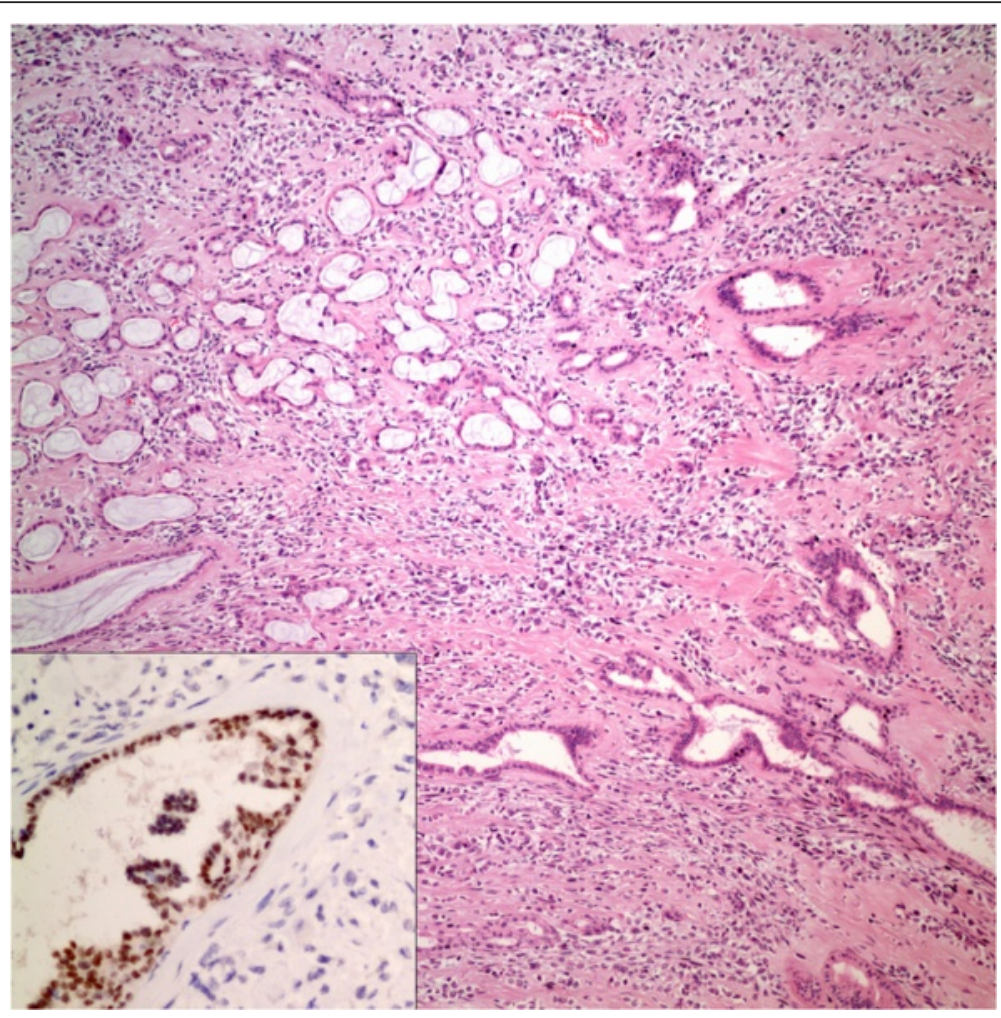

Fig. 9 Case \#2. Proliferating native renal tubules inside the tumor giving an appearance of a biphasic lesion (H\&E x 100). Inset shows that hyperplastic tubules maintain nuclear pax-8 (H\&E X 40) 


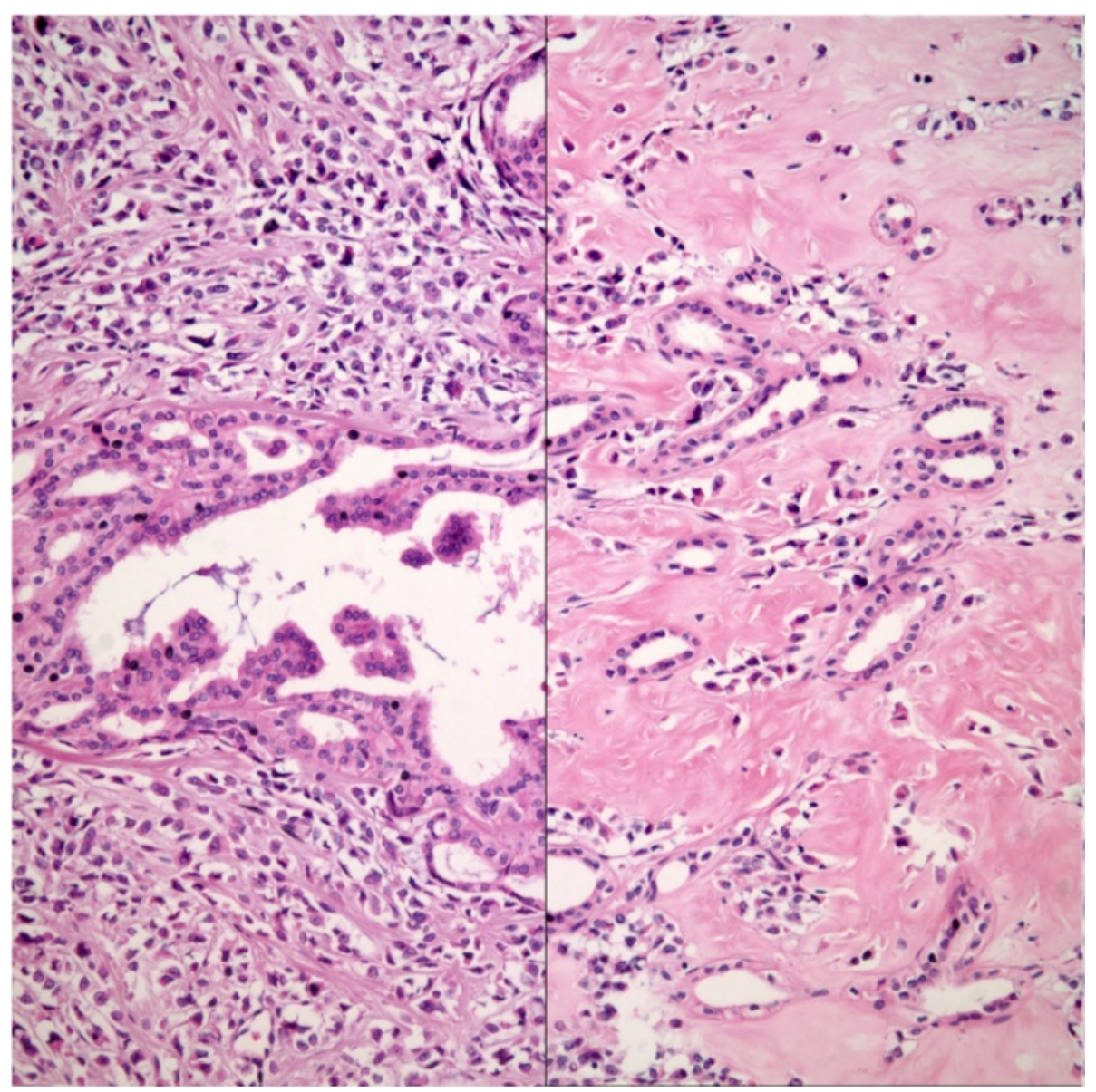

Fig. 10 Case \#2. Hyper and hypocellular regions (Left: H\&E x 200; Right: H\&E x 200)

however SEF and sclerosing type CCSK reveal both similar morphology and immunohistochemical findings Argani et al. suggest that some cases reported as sclerosing clear cell sarcoma of the kidney (CCSK) in the literature might in fact represent SEF [8].

SEF and low-grade fibromyxoid sarcoma (LGFMS) are thought to be related members in the fibrosing fibrosarcoma family [4]. Classic variants of LGFMS with or without giant rosettes constitute one end of the spectrum, characterized by a protracted clinical course and a low metastatic rate, whereas SEF or cellular variants of LGFMS constitute the other end which appears to be more aggressive. LGFMS may have SEF-like areas, and vice versa occurs in SEF lesions. Both tumors are labelled by immunohistochemical MUC4 staining, 99-100 \% in LGFMS and 78 \% in SEF, respectively $[2,16]$. Furthermore, a genetic link between sclerosing epithelioid fibrosarcoma and low-grade fibromyxoid sarcoma has been suggested [17]. Although majority $(>90 \%)$ of LGFMS and hybrid LGFMS/SEF harbor $\mathrm{t}(7 ; 16)(\mathrm{q} 33 ; \mathrm{p} 11)$ chromosome translocation resulting in FUS-CREB3L2 gene fusion, rare LGFMS carrying EWSR1-
CREB3L1 gene fusion with $\mathrm{t}(11 ; 22)(\mathrm{p} 11 ; \mathrm{q} 12)$ chromosome translocation was also found [18]. There have been 5 cases of primary LGFMS described in kidney or renal pelvis so far, one in a 6 year old child, others in adults [19-23].

We report 2 distinctive, clinically malignant, renal SEF bearing EWSR1-CREB3L1 fusions through unbalanced translocation with unique histomorphologic features. The common finding in both was the diffuse infiltration of the tumor among renal tubules and glomeruli filling out the space in-between them. Numerous tubules and also glomeruli were seen entrapped throughout the tumors. In case \#1, neoplastic cells surrounded these tubules in a concentric onion-skin like pattern giving a lobular or micronodular architecture to the lesion in many areas. Additionally, the neoplastic sleeves around tubules revealed a zonation pattern with inner hypocellular and outer hypercellular appearance. This was a wide-spread occurrence involving also the deeper parts of the tumor, so differed from what is seen in CCSK or metanephric stromal tumor where neoplasm encircles native tubules at the tumor infiltration borders in a 


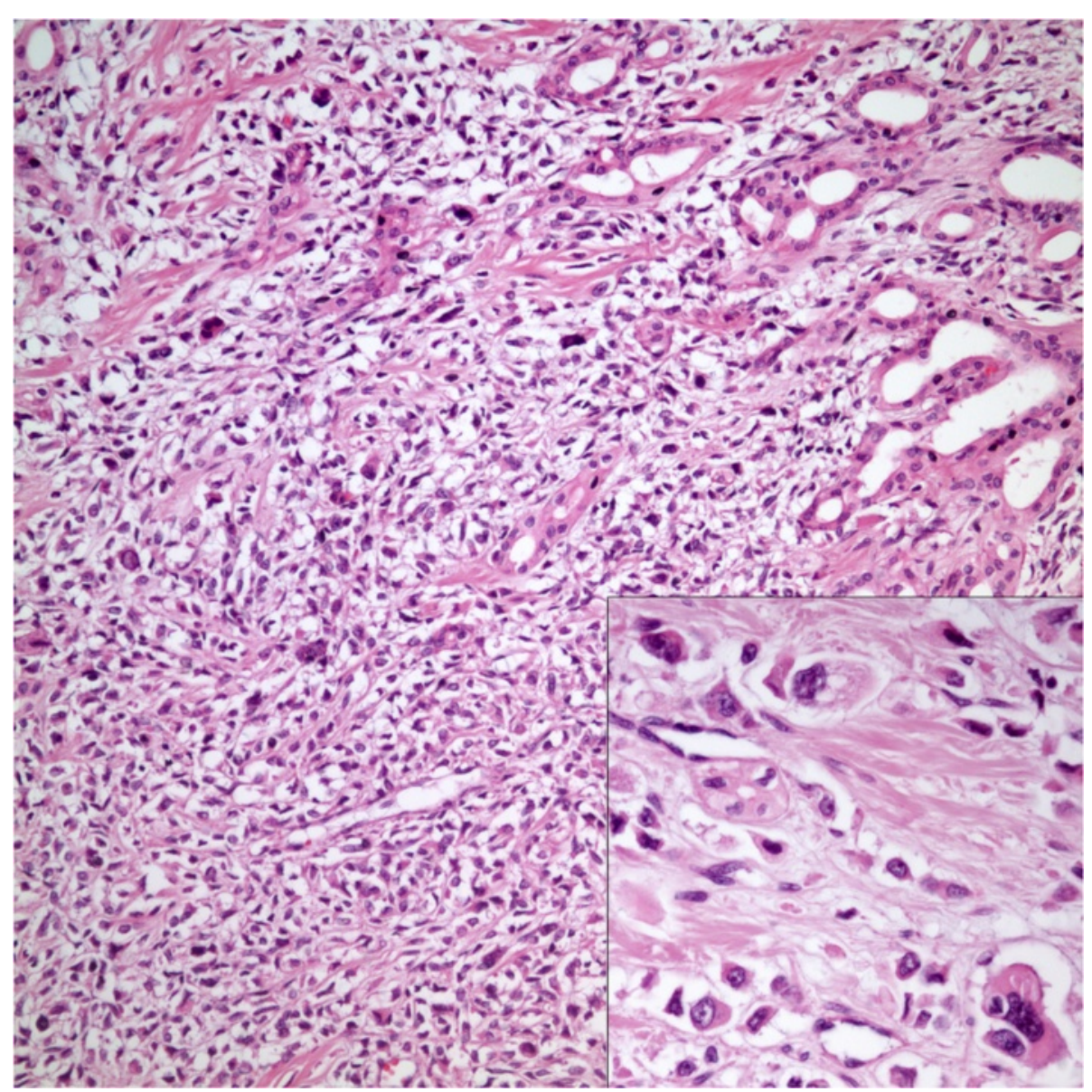

Fig. 11 Case \#2. Spindle cells forming short fascicles vaguely (H-E x 200). Inset highlights marked pleomorphism among the neoplastic cells (H-E x 400)

limited extent. No angiodysplasia or juxtaglomerular hyperplasia was found in our case.

The second case presented in this study varied from the first one in that the entrapped renal tubules exhibited prominent papillary hyperplasia and small gland budding which gave a biphasic appearance to the lesion. They were lined by cuboidal or flattened single layered epithelium devoid of atypia, some were cystic, and some looked fibroadenomatous and leaf-like due to compression by the interstitial neoplastic cells. It is quite likely that we would have diagnosed this lesion as malignant mixed epithelial and stromal tumor of kidney (MEST) only a few years ago when typical genetic alterations or MUC4 staining characteristic of this tumor type were unknown yet. In fact, we suspect that other examples of renal SEF may have been reported in the literature with an assignment as malignant MEST. Suzuki et al. [24] reported a malignant MEST in a male with a prostatic adenocarcinoma under anti-androgen treatment, that was composed of atypical small round cells with a high nuclear cytoplasmic ratio without necrosis and pleomorphism, and also focal spindle cells without cytologic atypia in a gradual transition to small round cells. Immunohistochemically, tumor was bcl-2 and CD99+, SMA and S-100 -. SYT-SSX1 and SYT-SSX2 chimeric transcript were not identified. We suspect that at least this published case may represent the entity reported herein.

Another feature of the second case of this study that varied from the first one and from 5 cases reported previously was the presence of high grade cytologic atypia with noteworthy pleomorphism and scattered bizarre tumor cells. Most SEFs are cytologically uniform tumors with scanty mitoses; however, it is stated that foci of pleomorphism -particularly in hybrid SEF and LGFMS cases- and high mitotic activity can rarely be encountered $[4,7,17]$.

SEF is frequently characterized by aggressive clinical behavior $[4,6]$. One or more local recurrences occur in approximately $50 \%$ of cases, with metastatic spread being reported in more than $40 \%$ of cases, most often affecting the pleura, lungs, bone and central nervous system. All of the cases reported previously except one and our first case were already metastatic at the time of presentation. As accurate recognition of SEF is important for appropriate patient management, we believe more cases need to be 


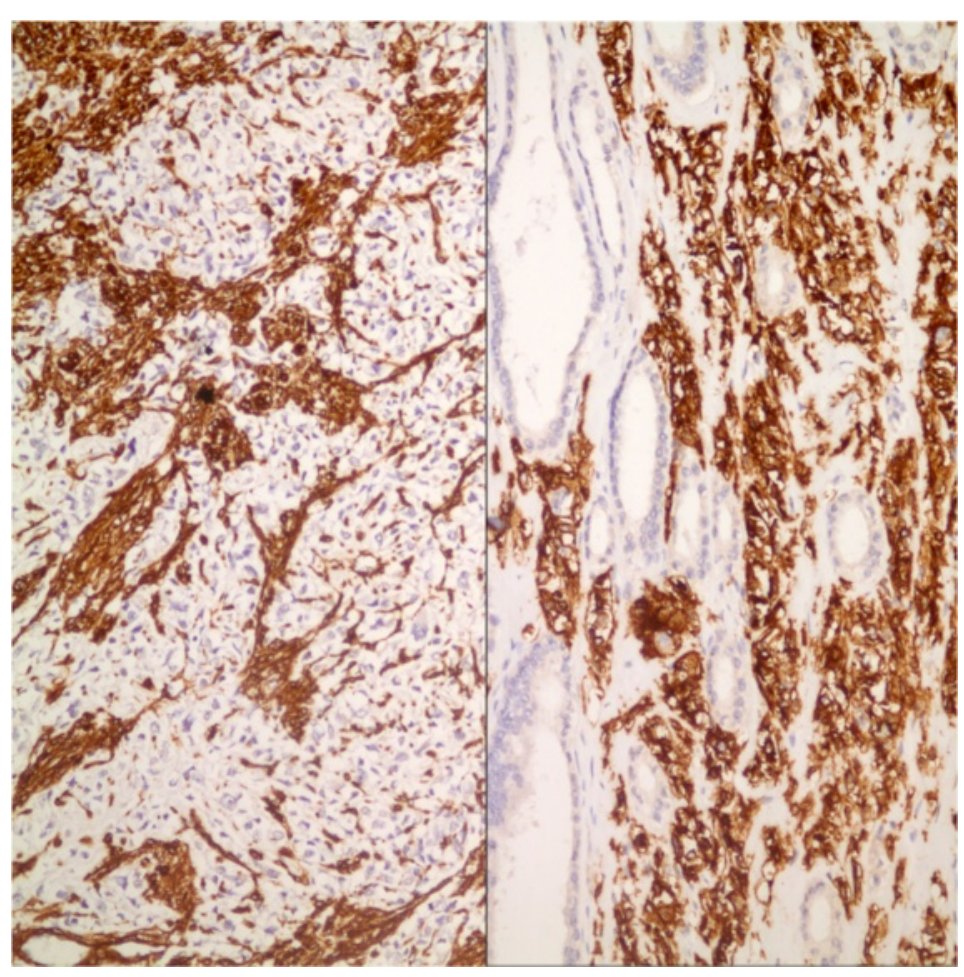

Fig. 12 Case \#2. SMA stains interspersed myofibroblasts and MUC4 labels neoplastic cells (Left: Immunohistochemistry, anti-SMA Ab x 200; Right: Immunohistochemistry, anti-MUC4 Ab x 200)

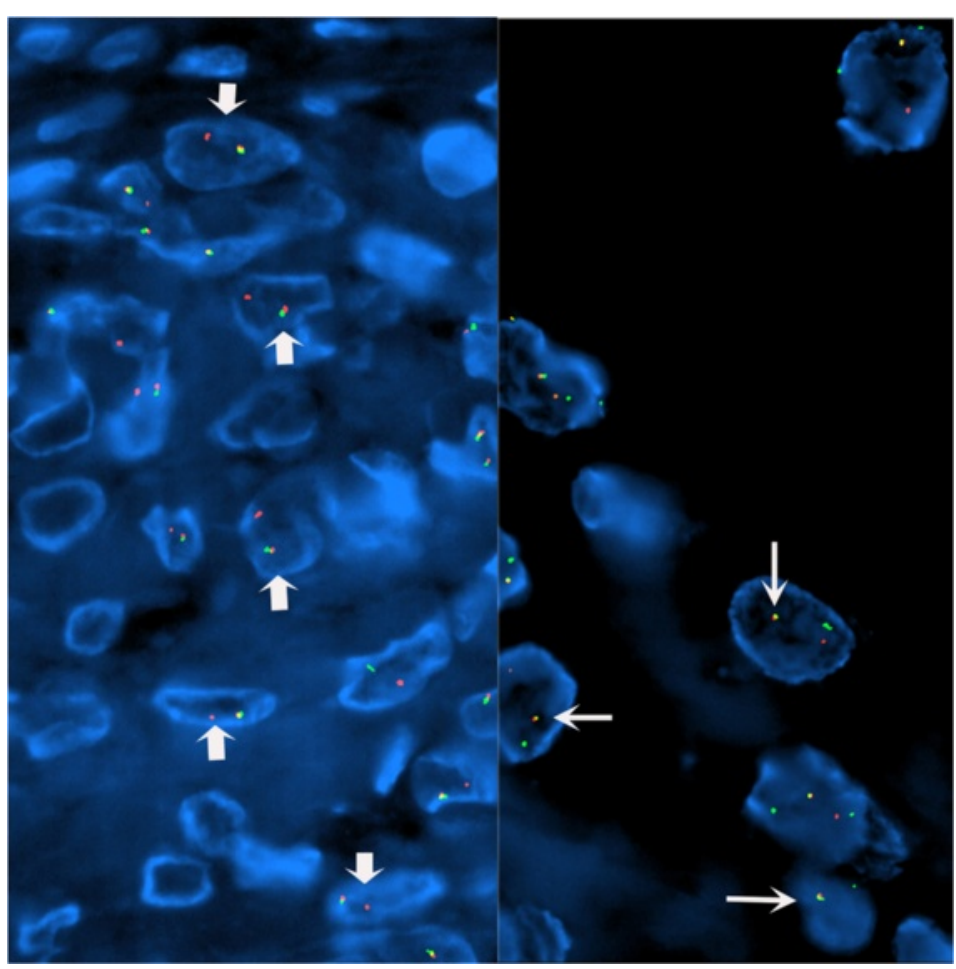

Fig. 13 Case \#2. FISH patterns similar to Case 1. EWSR1 break apart with loss of one copy of the Spectrum Green labeled probe flanking the $3^{\prime}$ (telomeric) side (left panel) and EWSR1/CREB3L1 fusion seen by a juxtaposed orange signal and green signal (right panel) 
Table 2 Summary of reported cases of primary renal SEF

\begin{tabular}{|c|c|c|c|c|c|c|c|c|}
\hline Authors & $\begin{array}{l}\text { Age } \\
\text { (years) }\end{array}$ & Gender & $\begin{array}{l}\text { Largest } \\
\text { Diameter } \\
\text { /Laterality }\end{array}$ & Clinical presentation & $\begin{array}{l}\text { FISH } \\
\text { Findings }\end{array}$ & Therapy & Metastases & $\begin{array}{l}\text { Outcome } \\
\text { (mo) }\end{array}$ \\
\hline Arbajian, et al. [1] & 41 & Female & $9 \mathrm{~cm} / \mathrm{NS}$ & NS & $\begin{array}{l}\text { EWSR1 Del } \\
3^{\prime}\end{array}$ & NS & Bone and lung & DOD (22) \\
\hline Argani, et al. [8] & 17 & Male & $25 \mathrm{~cm} / \mathrm{L}$ & $\begin{array}{l}\text { Left flank, back and abdominal pain, } \\
\text { weight loss, dysuria, and decreased } \\
\text { appetite }\end{array}$ & $\begin{array}{l}\text { EWSR1- } \\
\text { CREB3L1 } \\
\text { fusion }\end{array}$ & $\begin{array}{l}\text { Surgery } \\
+\mathrm{RT}\end{array}$ & $\begin{array}{l}\text { Rib, vertebrae, epidural } \\
\text { spinal cord and liver }\end{array}$ & $\mathrm{DOC}(1)$ \\
\hline Argani, et al. [8] & 61 & Female & $5 \mathrm{~cm} / \mathrm{L}$ & Rib pain & $\begin{array}{l}\text { EWSR1- } \\
\text { CERB3L1 } \\
\text { fusion }\end{array}$ & Surgery & $\begin{array}{l}\text { Ribs, bone, lung and } \\
\text { lymph nodes }\end{array}$ & AWD (6) \\
\hline $\begin{array}{l}\text { Ohlmann, et al. } \\
\text { [9] }\end{array}$ & 24 & Female & $22 \mathrm{~cm} / \mathrm{R}$ & NS & No results & $\begin{array}{l}\text { Surgery } \\
+R C T\end{array}$ & Lungs and vertebrae & DOD (82) \\
\hline $\begin{array}{l}\text { Ohlmann, et al. } \\
\text { [9] }\end{array}$ & 43 & Male & $4.2 \mathrm{~cm} / \mathrm{R}$ & Incidental & $\begin{array}{l}\text { EWSR1 } \\
\text { split }\end{array}$ & Surgery & None & ANED (8) \\
\hline $\begin{array}{l}\text { Ertoy Baydar, et } \\
\text { al. (present } \\
\text { case) }\end{array}$ & 16 & Female & $7.5 \mathrm{~cm} / \mathrm{L}$ & $\begin{array}{l}\text { Abdominal pain radiating to back on } \\
\text { the left }\end{array}$ & $\begin{array}{l}\text { EWSR1- } \\
\text { CREB3L1 } \\
\text { fusion }\end{array}$ & $\begin{array}{l}\text { Surgery } \\
+C T\end{array}$ & $\begin{array}{l}\text { Lungs, vertebrae, } \\
\text { sacrum and left } \\
\text { femoral head }\end{array}$ & AWD (30) \\
\hline $\begin{array}{l}\text { Ertoy Baydar, et } \\
\text { al. (present } \\
\text { case) }\end{array}$ & 57 & Female & $7.5 \mathrm{~cm} / \mathrm{L}$ & Incidental & $\begin{array}{l}\text { EWSR1- } \\
\text { CREB3L1 } \\
\text { fusion }\end{array}$ & Surgery & None & $\begin{array}{l}\text { ANED } \\
(10)\end{array}$ \\
\hline
\end{tabular}

NS Not specified, $L$ Left kidney, $R$ Right kidney, RT Radiotherapy, CT chemotherapy, RCT Radiochemotherapy, DOD Died of disease, DOC Died of complications related to disease treatment, AWD Alive with disease, ANED Alive with no evidence of disease

documented so that its full histomorphologic spectrum is uncovered.

\section{Conclusions}

Sclerosing epithelioid fibrosarcoma (SEF) is a rare soft tissue tumor that can occur in the kidney as a primary malignancy. Its misdiagnosis with other entities which are better known to develop in the kidney is a strong possibility as it has been only recently described and is unfamiliar to the pathologists. SEF is a neoplasm with variant morphological features that may overlap with many lesions confusingly. Immunohistochemistry and molecular studies that disclose the characteristic genetic alterations are crucial for accurate recognition.

Table 3 Morphology of SEF

\begin{tabular}{|c|c|}
\hline \multicolumn{2}{|l|}{ Typical features } \\
\hline Macroscopy & Large, homogeneously white or white-tan, lobulated, and hard tumors \\
\hline Cell size and shape & Small to medium-sized plump to epithelioid cells \\
\hline Cytoplasm & Scant clear or eosinophilic cytoplasm \\
\hline Nuclei & Oval to slightly elongate angulated nuclei with finely speckled chromatin \\
\hline Cellularity & Variable within the neoplasm \\
\hline Atypia & Mild \\
\hline Matrix & Densely sclerotic, areas of metaplastic bone in some \\
\hline Pattern of cellular arrangement & Small clusters, nests and anastomosing cords \\
\hline Hybrid morphology & Areas of LGFMS or nodules of collagen reminiscent of HSCTGR in some \\
\hline Immunohistochemistry & MUC4 ++, EMA +/-, CD99 +/-, bcl2 +/-, pan-keratin -, S100/HMB45/MelanA - \\
\hline $\mathrm{FISH}$ & EWSR1 (or rarely FUS) rearrangements \\
\hline \multicolumn{2}{|c|}{ Previously unrecognized features in renal SEF } \\
\hline \multirow[t]{2}{*}{ Current case 1} & A lobular or micronodular architecture due to neoplastic cells surrounding entrapped renal tubules in a concentric fashion \\
\hline & Zonation in the neoplastic lobules around tubules with inner hypocellular and outer hypercellular appearance \\
\hline \multirow[t]{2}{*}{ Current case 2} & Exuberant epithelial hyperplasia and small gland budding in the entrapped native renal tubules, mimicking MEST \\
\hline & High grade cytologic atypia \\
\hline
\end{tabular}




\section{Consent}

Written informed consent was obtained from the parent (case \#1) and the patient (case \#2) for publication of this Case Report and any accompanying images. A copy of the written consent is available for review by the Editor-inChief of this journal.

\section{Abbreviations}

SEF: Sclerosing epithelioid fibrosarcoma; FISH: Fluorescence in situ hybridization; HSCTGR: Hyalinizing spindle cell tumor with giant rosettes; CT: Computerized tomography; CCSK: Clear cell sarcoma of the kidney; LGFMS: Low-grade fibromyxoid sarcoma; MEST: Mixed epithelial and stromal tumor of kidney.

\section{Competing interest}

The authors declare that they have no competing interest.

\section{Authors' contribution}

$\mathrm{DEB}, \mathrm{KK}, \mathrm{OA}$ and $\mathrm{BB}$ performed the histological examination. FTA and OA analyzed and interpreted the patients' data. JAB performed FISH analysis and figures. DEB drafted the manuscript. KK made substantial contribution to analysis. All authors read and approved the final manuscript.

\section{Acknowledgment}

The authors thank Jonathan I. Epstein, M.D. and Pedram Argani, M.D. (The Johns Hopkins Medical Institutions, Baltimore, MD) who reviewed first case and provided a significant diagnostic input.

The authors also would like to thank Dr. Irina Vaysertreyger, Dr. Dali Huang, and Dr. Yimin Sun for their expert technical assistance.

\section{Author details}

'Department of Pathology, Hacettepe University Hospital, Ankara, Turkey. ${ }^{2}$ Department of Pathology, Ondokuz Mayis University Hospital, Samsun, Turkey. ${ }^{3}$ Departments of Pathology/Microbiology, Pediatrics and Orthopaedic Surgery, Nebraska Medical Center, Omaha, NE, USA. ${ }^{4}$ Department of Urology, Hacettepe University Hospital, Ankara, Turkey.

Received: 1 August 2015 Accepted: 1 October 2015

Published online: 09 October 2015

\section{References}

1. Arbajian E, Puls F, Magnusson L, Thway K, Fisher C, Sumathi VP, et al. Recurrent EWSR1-CREB3L1 gene fusions in sclerosing epithelioid fibrosarcoma. Am J Surg Pathol. 2014;38(6):801-8. doi:10.1097/PAS.0000000000000158.

2. Doyle LA, Wang WL, Dal Cin P, Lopez-Terrada D, Mertens F, Lazar AJ, et al. MUC4 is a sensitive and extremely useful marker for sclerosing epithelioid fibrosarcoma: association with FUS gene rearrangement. Am J Surg Pathol. 2012:36(10):1444-51. doi:10.1097/PAS.0b013e3182562bf8.

3. Prieto-Granada C, Zhang L, Chen HW, Sung YS, Agaram NP, Jungbluth AA, et al. A genetic dichotomy between pure sclerosing epithelioid fibrosarcoma (SEF) and hybrid SEF/low-grade fibromyxoid sarcoma: A pathologic and molecular study of 18 cases. Genes Chromosomes Cancer. 2014. doi:10.1002/gcc.22215.

4. Antonescu CR, Rosenblum MK, Pereira P, Nascimento AG, Woodruff JM. Sclerosing epithelioid fibrosarcoma: a study of 16 cases and confirmation of a clinicopathologically distinct tumor. Am J Surg Pathol. 2001;25(6):699-709.

5. Chow LT, Lui YH, Kumta SM, Allen PW. Primary sclerosing epithelioid fibrosarcoma of the sacrum: a case report and review of the literature. J Clin Pathol. 2004:57(1):90-4.

6. Meis-Kindblom JM, Kindblom LG, Enzinger FM. Sclerosing epithelioid fibrosarcoma. A variant of fibrosarcoma simulating carcinoma. Am J Surg Pathol. 1995:19(9):979-93.

7. Ossendorf C, Studer GM, Bode B, Fuchs B. Sclerosing epithelioid fibrosarcoma: case presentation and a systematic review. Clin Orthop Relat Res. 2008;466(6):1485-91. doi:10.1007/s11999-008-0205-8.

8. Argani P, Lewin JR, Edmonds P, Netto GJ, Prieto-Granada C, Zhang L, et al. Primary Renal Sclerosing Epithelioid Fibrosarcoma: Report of 2 Cases With EWSR1-CREB3L1 Gene Fusion. Am J Surg Pathol. 2014. doi:10.1097/PAS.0000000000000338.
9. Ohlmann $\mathrm{CH}$, Brecht IB, Junker $\mathrm{K}$, van der Zee JA, Nistor A, Bohle RM, et al. Sclerosing epithelioid fibrosarcoma of the kidney: clinicopathologic and molecular study of a rare neoplasm at a novel location. Ann Diagn Pathol. 2015. doi:10.1016/j.anndiagpath.2015.04.005.

10. Bai S, Jhala N, Adsay NV, Wei S. Sclerosing epithelioid fibrosarcoma of the pancreas. Ann Diagn Pathol. 2013;17(2):214-6. doi:10.1016/ j.anndiagpath.2011.06.006.

11. Frattini JC, Sosa JA, Carmack S, Robert ME. Sclerosing epithelioid fibrosarcoma of the cecum: a radiation-associated tumor in a previously unreported site. Arch Pathol Lab Med. 2007;131(12):1825-8. doi:10.1043/ 1543-2165(2007)131[1825:SEFOTC]2.0.CO;2

12. Tomimaru $Y$, Nagano H, Marubashi S, Kobayashi S, Eguchi H, Takeda Y, et al. Sclerosing epithelioid fibrosarcoma of the liver infiltrating the inferior vena cava. World J Gastroenterol. 2009;15(33):4204-8.

13. Wojcik JB, Bellizzi AM, Dal Cin P, Bredella MA, Fletcher CD, Hornicek FJ, et al. Primary sclerosing epithelioid fibrosarcoma of bone: analysis of a series. Am J Surg Pathol. 2014;38(11):1538-44. doi:10.1097/PAS.0000000000000265.

14. Watanabe K, Suzuki T. Epithelioid fibrosarcoma of the ovary. Virchows Arch. 2004:445(4):410-3. doi:10.1007/s00428-004-1068-3.

15. Goldblum JR, Folpe AL, Weiss SW. Borderline and Malignant Fibroblastic/ Myofibroblastic Tumors. In: Goldblum JR, Folpe AL, Weiss SW, editors. Enzinger and Weiss's soft tissue tumors. 6th ed. Philadelphia, PA: Saunders/ Elsevier; 2014. p. 288-340.

16. Doyle LA, Moller E, Dal Cin P, Fletcher CD, Mertens F, Hornick JL. MUC4 is a highly sensitive and specific marker for low-grade fibromyxoid sarcoma. Am J Surg Pathol. 2011:35(5):733-41. doi:10.1097/PAS.0b013e318210c268.

17. Guillou L, Benhattar J, Gengler C, Gallagher G, Ranchere-Vince D, Collin F, et al. Translocation-positive low-grade fibromyxoid sarcoma: clinicopathologic and molecular analysis of a series expanding the morphologic spectrum and suggesting potential relationship to sclerosing epithelioid fibrosarcoma: a study from the French Sarcoma Group. Am J Surg Pathol. 2007;31(9):1387-402. doi:10.1097/PAS.0b013e3180321959.

18. Lau PP, Lui PC, Lau GT, Yau DT, Cheung ET, Chan JK. EWSR1-CREB3L1 gene fusion: a novel alternative molecular aberration of low-grade fibromyxoid sarcoma. Am J Surg Pathol. 2013;37(5):734-8. doi:10.1097/ PAS.0b013e31827560f8.

19. Alevizopoulos A, Mygdalis V, Tyritzis S, Stravodimos K, Constantinides CA. Low-grade fibromyxoid sarcoma of the renal pelvis: first report. Case Rep Nephrol Urol. 2012:2(2):87-91. doi:10.1159/000341191.

20. Arancio M, Ranzoni S, Delsignore A, Maffei N, Landi G, Mina A, et al. Fibromyxoid sarcoma of the kidney. A case report. Urologia. 2010;77(4):263-6.

21. del Valle GN, Santos Largo J, Martinez-Sagarra Oceja J, Rodriguez TV. Fibromyxoid sarcoma of kidney. Actas Urol Esp. 2009;33(9):1036-9.

22. Rubinstein JC, Visa A, Zhang L, Antonescu CR, Christison-Lagay ER, Morotti R. Primary Low-Grade Fibromyxoid Sarcoma of the Kidney in a Child with the Alternative EWSR1-CREB3L1 Gene Fusion. Pediatr Dev Pathol. 2014;17(4):321-6. doi:10.2350/14-05-1487-CR.1.

23. Silverman JF, Nathan G, Olson PR, Prichard J, Cohen JK. Fine-needle aspiration cytology of low-grade fibromyxoid sarcoma of the renal capsule (capsuloma). Diagn Cytopathol. 2000;23(4):279-83.

24. Suzuki T, Hiragata S, Hosaka K, Oyama T, Kuroda N, Hes O, et al. Malignant mixed epithelial and stromal tumor of the kidney: report of the first male case. Int J Urol. 2013;20(4):448-50. doi:10.1111/j.1442-2042.2012.03155.x.

\section{Submit your next manuscript to BioMed Central and take full advantage of:}

- Convenient online submission

- Thorough peer review

- No space constraints or color figure charges

- Immediate publication on acceptance

- Inclusion in PubMed, CAS, Scopus and Google Scholar

- Research which is freely available for redistribution 